\title{
Expression of the carotenoid biosynthesis genes in Xanthophyllomyces dendrorhous
}

\author{
LODATO P, ALCAÍNO, J, BARAHONA, S NIKLITSCHEK, M, CARMONA, M, \\ WOZNIAK, A, BAEZA, M, JIMÉNEZ, A and CIFUENTES V*
}

Departamento de Ciencias Ecológicas, Facultad de Ciencias, Universidad de Chile, Casilla 653, Santiago, Chile.

\begin{abstract}
In the yeast Xanthophyllomyces dendrorhous the genes idi, crtE, crtYB, crtI and ast are involved in the biosynthesis of astaxanthin from isopentenyl pyrophosphate. The carotenoid production and the kinetics of mRNA expression of structural genes controlling the carotenogenesis in a wild-type ATCC 24230 and in carotenoid overproducer deregulated atxS2 strains were studied. The biosynthesis of carotenoid was induced at the late exponential growth phase in both strains. However, the cellular carotenoid concentration was four times higher in atxS2 than in the wild-type strain in the exponential growth phase, suggesting that carotenogenesis was deregulated in atxS2 at the beginning of growth. In addition, the maximum expression of the carotenogenesis genes at the mRNA level was observed during the induction period of carotenoid biosynthesis in the wild-type strain. The mRNA level of the $\operatorname{crt} Y B$, crtI, ast genes and to a lesser extent the idi gene, decayed at the end of the exponential growth phase. The mRNA levels of the $c r t E$ gene remained high along the whole growth curve of the yeast. In the atxS2 strain the mRNA levels of crtE gene were about two times higher than the wild-type strain in the early phase of the growth cycle.
\end{abstract}

Key terms: Xanthophyllomyces dendrorhous, carotenogenesis genes, mRNA expression.

\section{INTRODUCTION}

Astaxanthin (3,3'-dihydroxy- $\beta$ - $\beta$ ' -carotene$4,4^{\prime}$-dione) is a natural and one of the most important pigments responsible for the orange - red color of animals such as invertebrates, fish and birds. This xanthophyll has a high biotechnological interest, mainly in the aquaculture industry since farmed salmons and trouts are unable to synthesize this compound (Johnson 1977, Lorenz and Cysewski, 2000, Miller et al., 1976). In addition, this pigment performs a series of critical roles in the photosystem structure, light harvesting, photoprotection, inactivation of free radicals and has powerful antioxidant properties, having a beneficial effect on human health (Nigoyi et al., 1997). Astaxanthin biosynthesis has been observed in few microorganisms such as bacteria, the algae Haematococcus pluvialis, and the red yeast Xanthophyllomyces dendrorhous (Armstrong, 1994). These later organisms have a potential use as microbial systems for the commercial production of astaxanthin (Johnson, 2003). However, the specific production of astaxanthin by wildtype strains of $X$. dendrorhous is too low (200 - $400 \mu \mathrm{g}$ per $\mathrm{g}$ of dry yeast) to be used at an industrial scale. Therefore, many investigators have made an effort to improve the production of astaxanthin by $X$. dendrorhous, including the optimization of culture parameters such as glucose concentration, $\mathrm{pH}$, oxygen, carbon/nitrogen ratio (Johnson and Lewis 1979, 41, An et al., 1989, An and Johnson, 1990, Miura et al., 1998, Johnson, 2003) and by classical random mutagenesis methods (Retamales et al., 1998, 2002, 2003, An et al., 1989, Lewis et al., 1990, An, 1997, Bon et al., 
1997). Although a significant increase in the production of astaxanthin has been obtained with these experimental approximations, little is known about the genetic processes controlling the astaxanthin biosynthesis pathway in $X$. dendrorhous.

While bacteria and plants require between six to eight genes to synthesize astaxanthin from IPP, X. dendrorhous could require only five genes for the same process. In $X$. dendrorhous, the biosynthesis of astaxanthin derives from the isoprenoid synthesis pathway and begins with the synthesis of dimethylallyl pirophosphate (DMAPP) by IPP isomerase, followed by the sequential addition of three molecules of IPP to give the $\mathrm{C}_{20}$-precursor geranylgeranyl pirophosphate (GGPP), step catalyzed by the GGPP synthase. These enzymes are coded by the idi (Kajiwara et al., 1997) and crtE genes respectively. The first specific and crucial step of the carotenogenic pathway is the synthesis of phytoene, through the condensation of two molecules of GGPP, catalyzed by the bifunctional enzyme phytoene synthase lycopene ciclase encoded by the $\operatorname{crt} Y B$ gene (Verdoes et al., 1999a). Through four dehydrogenation and two cyclization reactions the phytoene is converted to $\beta$ carotene by the action of phytoene desaturase enzyme and lycopene cyclase activity encoded by the crtI and $\operatorname{crt} Y B$ genes respectively (Verdoes et al., 1999b). Finally, $\beta$-carotene is converted to astaxanthin by four enzymatic reactions through the addition of two hydroxyl and two keto groups, steps catalyzed by a genetic product of the ast gene. Our knowledge on the regulation of the carotenogenic gene expression in $X$. dendrorhous is limited. In previous works, it was determined that the crtI mRNA and crtYB mRNA levels decreased during the stationary phase of $X$. dendrorhous (Lodato et al., 2003). However, the carotenoid production differences between wild type and astaxanthin overproducing strains of $X$. dendrorhous could not be explained by a difference in the carotenogenic transcripts at the stationary growth phase (Lodato et al., 2004). So, the kinetic study of the expression at the mRNA level of each gene implicated in the production of astaxanthin in different culture conditions and in asthaxanthin-overproducing strains will allow the selection of gene targets to be genetically manipulated and thus improve the astaxanthin production in this yeast.

\section{MATERIALS AND METHODS}

\section{Yeast strains}

$X$. dendrorhous strain ATCC 24230 (UCD 67-385) was used as wild type. Strain atxS2 corresponds to a carotenoid over-producing mutant obtained by mutagenesis with Nmethyl-N'-nitro-nitrosoguanidine (NTG) from the wild type strain of $X$. dendrorhous (Lodato et al., 2004).

\section{Culture conditions}

Wild-type and atxS2 strains were grown in a batch culture fermentor at $22{ }^{\circ} \mathrm{C}$. For each strain, $400 \mathrm{ml}$ of two day old pre-culture was prepared in a 1 l baffled flask containing YM medium (An et al., 1989), by inoculation with $4 \mathrm{ml}$ of a two day culture (Lodato et al., 2003). A 121 jar fermentor (New Brunswick) containing 8,8 1 of YM medium and $450 \mathrm{ml}$ of silicone antifoam agent (1520 US, Dow Corning), was inoculated with $200 \mathrm{ml}$ of the preculture. The cultures were grown at $22{ }^{\circ} \mathrm{C}$ shaking at $300 \mathrm{rpm}$ and $8 \mathrm{l} / \mathrm{ml}$ sterile air injection. The antifoam agent was automatically added when required. Culture samples were collected at different times and centrifuged at $1,300 \mathrm{x} \mathrm{g}$ for $10 \mathrm{~min}$. The cellular pellets were immediately frozen in liquid nitrogen and stored at -70 ${ }^{\circ} \mathrm{C}$ until carotenoid and RNA extraction. A Neubauer chamber was used for cell counts.

\section{Total carotenoid extraction}

The extraction was carried out from cellular pellets according to the acetone extraction method (An et al., 1989). Carotenoids were quantified by absorbance at $474 \mathrm{~nm}$ using an absorption coefficient of $\mathrm{A}_{1 \%}=2,100$. The analyses were performed in triplicate 
and pigments were normalized relative to the dry weight of the yeast.

\section{Glucose and ethanol quantification}

The UV method (Boehringer Mannheim) for glucose and ethanol quantification was used. The determination is based on the enzymatic oxidation of glucose to Dgluconate-6-phosphate or ethanol to acetic acid, with stoichiometric formation of NADPH and NADH respectively. The quantity of glucose or ethanol was calculated by light absorbance at $340 \mathrm{~nm}$ of $\mathrm{NADPH}$ or $\mathrm{NADH}$ respectively in a Shimadzu UV 150-02 spectrophotometer. The reactions were performed according to the manufacturer's instructions using appropriate dilutions of cell-free culture media as substrate. The ratio between relative production of carotenoid and ethanol was calculated as the ratio of carotenoid ( $\mathrm{mg} / \mathrm{g}$ dry yeast) at time $\mathrm{t} /$ carotenoid maximum with respect to the ratio of production of ethanol at time $t$ / maximum ethanol production.

\section{Total RNA extraction}

The cellular pellets obtained from $40 \mathrm{ml}$ aliquots of culture were utilized for the extraction of total RNA by a modified protocol of Chomczynski and Sacchi (Chomczynski and Sacchi, 1987, Lodato et al., 2003, Lodato et al., 2004). The total RNA concentration was determined at 260 $\mathrm{nm}$ and the purity was determined by the ratio at 260: $230 \mathrm{~nm}$ and 260: $280 \mathrm{~nm}$ greater than 1.8 (Sambrook et al., 1989). The integrity of the RNA was checked by denaturant agarose gel electrophoresis, determining the proportion of the $28 \mathrm{~S}$ : $18 \mathrm{~S}$ ribosomal RNA bands to be about 2.0 (Sambrook et al., 1989).

\section{cDNA synthesis ( $R T$ reaction)}

RNA samples were treated with $1 \mathrm{U}$ of DNase I (Roche) in $2.5 \mathrm{mM} \mathrm{MgCl} 2$ at $25^{\circ} \mathrm{C}$ for $30 \mathrm{~min}$. The reaction was stopped by the addition of EDTA at $2.5 \mathrm{mM}$ final concentration and heating at $65{ }^{\circ} \mathrm{C}$ for 15 min. The reverse transcriptase reaction was performed in $25 \mu \mathrm{l}$ final volume with $3 \mu \mathrm{g}$ of total RNA, 75 pmoles oligo dT15-18, 0.5 $\mathrm{mM}$ of dNTPs and $200 \mathrm{U}$ of M-MLV reverse transcriptase (Promega) (Lodato et al., 2003, 2004). The reaction mixture was incubated at $42{ }^{\circ} \mathrm{C}$ for $60 \mathrm{~min}$ and then heated to $65^{\circ} \mathrm{C}$ for $10 \mathrm{~min}$.

PCR amplification from cDNA of carotenoid biosynthesis genes

The determination of the relative levels of mRNAs of carotenoid biosynthesis genes was performed by a semi-quantitative RTPCR method using the primers described in Table 1. These primers were designed according to the published sequences of the CBS 6938 (Verdoes et al, 1999a; 1999b) and ATCC 24230 (Kajiwara et al, 1997; Lodato et al, 2003 and this work) $X$. dendrorhous wild-type strains. The GenBank accession numbers are: AB019035, Y15007, AJ133646, A63889, DQ012943, DQ016503, DQ028748, DQ002006, DQ016502, DQ002007, AY177424, AY177425, AY 177204 and AY 174117. The PCR reactions were performed according to the experimental conditions previously described (Lodato et al., 2003; 2004) in a final volume of $25 \mu \mathrm{l}$ containing $2 \mathrm{U}$ of Taq pol (Promega), $2.5 \mu \mathrm{l}$ of $10 \mathrm{X}$ Taq buffer, $0.5 \mu \mathrm{l}$ of $10 \mathrm{mM}$ dNTPs, $1 \mu \mathrm{l}$ of $50 \mathrm{mM} \mathrm{MgCl}{ }_{2}, 1 \mu \mathrm{l}$ of 25 $\mu \mathrm{M}$ of each primer and 1 or $2 \mu \mathrm{l}$ single strand cDNA from the $\mathrm{RT}$ reaction. The final volume was adjusted with distilled water. Amplification was performed in a DNA Thermal Cycler 2400 (Perkin-Elmer) as follows: initial denaturation at $95{ }^{\circ} \mathrm{C}$ for $3 \mathrm{~min} ; 28$ cycles of denaturation at $94{ }^{\circ} \mathrm{C}$ for $30 \mathrm{~s}$, annealing at $55{ }^{\circ} \mathrm{C}$ for $30 \mathrm{~s}$, synthesis at $72{ }^{\circ} \mathrm{C}$ for $3 \mathrm{~min}$ and a final extension step at $72{ }^{\circ} \mathrm{C}$ for $10 \mathrm{~min}$. For the crtI and ast primers the annealing temperature was 60 and $57{ }^{\circ} \mathrm{C}$ respectively. Negative control reactions without DNA from the RT reaction, were carried out simultaneously. The PCR products were separated electrophoretically in 3\% agarose gels in TAE buffer containing ethidium bromide $(0.5 \mu \mathrm{g} / \mathrm{ml})$ or $4.5 \%$ polyacrylamide (cDNA from $c r t \mathrm{YB}$ ) and photographed under UV light. The mass of 
the bands was quantified by the 1D Image Analysis Software version 2.0.1 (Kodak Scientific Imagen System) using the $100 \mathrm{bp}$ DNA Ladder (Fermentas) as standard. All reactions were performed in duplicate or triplicate. To normalize for sample to sample variation due to RT and PCR efficiency, relative values were obtained by comparing the intensities of the carotenogenesis gene amplification bands with the intensity of the actin amplification product (Lodato et al, 2003; Ngiam et al., 2000), which was co-amplified in each PCR reaction using primers ACT3 and ACT4 (Table 1), designed according to the published sequence of $X$. dendrorhous with GenBank accession number X89898 (Wery et al., 1996). The level of expression of the act gene was constant throughout the yeast growth cycle. In the kinetics expression curve of each carotenoid biosynthetic gene, each value was normalized with respect to the highest value obtained in the curve which was given a score of 1 .

\section{RESULTS}

Carotenoids and ethanol production, and glucose consumption in $X$. dendrorhous cultures

The growth curve of wild-type ATCC 24230 and overproducer atxS2 strains of $X$. dendrorhous during batch cultivation in glucose is shown on Figure 1. Additionally, the consumption of glucose, production and consumption of ethanol and the point of carotenoid biosynthesis induction is shown. A decrease in glucose concentration in the culture media during the log phase is observed in both cultures together with an accumulation of ethanol. The complete consumption of glucose coincides with the entrance into stationary phase, corresponding approximately to 27 and $36 \mathrm{~h}$ for the wild type and atxS2 strains respectively. In both strains, ethanol production started after $18 \mathrm{~h}$ of growth and accumulated during log phase until it was

TABLE 1

Primers used in RT-PCR reactions to determine mRNA levels of carotenogenesis genes.

\begin{tabular}{|c|c|c|c|c|}
\hline Gene & Primer & Direction $^{\mathrm{a}}$ & Sequence $\left(5^{\prime} \rightarrow 3^{\prime}\right)$ & Location \\
\hline \multirow[t]{2}{*}{ act } & ACT3 & $\mathrm{F}$ & АСTCCTACGTTGGTGACGAG & Spanning exons 4 and 5 (1445) \\
\hline & ACT4 & $\mathrm{R}$ & TCAAGTCTCGACCGGCCAAG & Exon 5 \\
\hline \multirow[t]{4}{*}{$\operatorname{crt} \mathrm{I}$} & 2 & $\mathrm{~F}$ & AGCTATCATCGTGGGATGTGGb & Spanning exons 1 and 2 (764) \\
\hline & 4 & $\mathrm{~F}$ & AGCTATCATCGTGGTTTAATCC & Spanning exon 1 and intron 1 (764) \\
\hline & 6 & $\mathrm{R}$ & GACCСААТСТTCCАТСТTСTCT & Exon 5 (1882) \\
\hline & 7 & $\mathrm{R}$ & TTCTCGAACACCGTGACCT & Exon 2 (1099) \\
\hline \multirow[t]{3}{*}{$\operatorname{crt} \mathrm{YB}$} & 11 & $\mathrm{~F}$ & GСАTATTACCAGATCCATCTGb & Spanning exons 1 and 2 (1301) \\
\hline & 12 & $\mathrm{~F}$ & GTGTGCATATGTGTTGCAACC ${ }^{\mathrm{C}}$ & Spanning intron 1 and exon 2 (1176) \\
\hline & 15 & $\mathrm{R}$ & TCTAGAAACGTTCCAAACACG & Exon 2 (1432) \\
\hline \multirow[t]{2}{*}{$\operatorname{crt} \mathrm{E}$} & 21 & $\mathrm{~F}$ & TTCAGTCTTCTGAGTATGCCC & Spanning exons 1 and 2 (830) \\
\hline & 22 & $\mathrm{R}$ & CATTGCGAGAAGACGAAGACT & Exon 3 (1494) \\
\hline \multirow[t]{2}{*}{$i d i$} & 31 & $\mathrm{~F}$ & TACGATGAGGAGCAGGTCAG & Spanning exons 1 and 2 (1044) \\
\hline & 32 & $\mathrm{R}$ & CCGAGAGATCCTCCAACGAT & Exon 5 (2232) \\
\hline \multirow[t]{2}{*}{ ast } & 41 & $\mathrm{~F}$ & GCСАССТАСТTTСTCСАТАTGT & Upstream translation initiation (517) \\
\hline & 42 & $\mathrm{R}$ & GAGCCATGACGTCCAGAGTA & Exon 6 (1609) \\
\hline
\end{tabular}

${ }^{\mathrm{a}}$, F: forward, R: reverse; ${ }^{\text {b }}$, specific for mmRNA; ${ }^{\mathrm{c}}$, specific for amRNA. 
consumed when glucose was totally depleted from the media in the wild-type cultures. However, in atxS2, ethanol utilization began when the glucose level was about $23 \%$ from its initial concentration and had a greater carotenoid and ethanol production compared to the parental strain (Table 2). The induction of carotenoid biosynthesis occurred at the end of the log phase coinciding with glucose depletion from the culture media of both strains (arrows on Figure 1). The carotenoid production in relation to ethanol consumption, for each sampling time was calculated as the ratio of carotenoid $(\mu \mathrm{g} / \mathrm{g}$ dry yeast) with respect to their maximum production and ethanol ratio with respect to their highest value. In addition, the production of carotenoids in atxS2 in the log phase was four times higher than in wild-type cultures. Furthermore, for atxS2, carotenoid synthesis continued to increase until the end of the experiment (65 h), while the wild-type strain reached a plateau at approximately $48 \mathrm{~h}$.
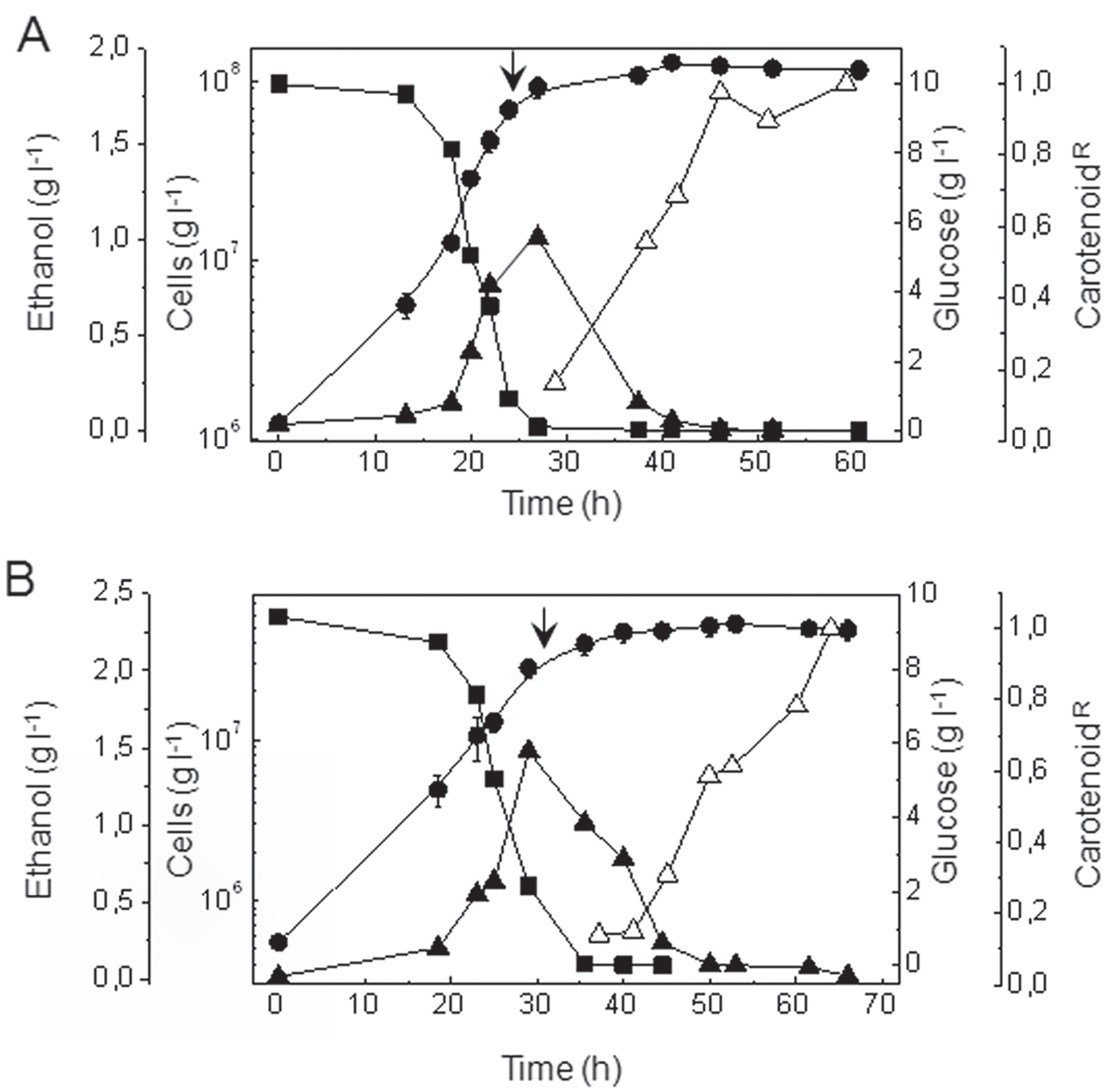

Figure 1: Glucose consumption and ethanol production along the growth curve of $X$. dendrorhous strains. The wild type UCD 67-385 (A) and mutant atxS2 (B) strains were grown in YM media in a batch fermentor at $22{ }^{\circ} \mathrm{C}$. ( $)$, number of cells; ( $\left.\mathbf{\square}\right)$, glucose; $(\mathbf{\Delta})$, ethanol. The ratio between relative production of carotenoid and ethanol $(\Delta)$ was calculated as described in materials and methods. Arrows indicate the point of carotenoid biosynthesis induction. Carotenoid ${ }^{\mathrm{R}}$ : The carotenoid production in relation to ethanol consumption. 
TABLE 2

Biomass, carotenoids and ethanol production by wild-type and atx 2 strains of $X$. dendrorhous.

\begin{tabular}{lllll}
\hline Strains & Biomass & \multicolumn{2}{c}{ Carotenoids $(\mu \mathrm{g} / \mathrm{g}$ dry yeast $)$} & \multicolumn{2}{c}{$\begin{array}{l}\text { Ethanol } \\
\text { Dry weight }(\mathrm{mg} / \mathrm{ml})\end{array}$} & Exponential phase & Stationary phase & $(\mathrm{g} / \mathrm{g}$ dry yeast $)$ \\
\hline ATCC 24230 (1) & $6,62 \pm 0,08$ & $42 \pm 0,93$ & $186 \pm 7,6$ & 0,214 \\
atxS2 (2) & $5,61 \pm 0,18$ & $173 \pm 5$ & $426 \pm 6,7$ & 0,523 \\
$(2) /(1)$ ratio & 0,85 & 4,12 & 2,3 & 2,44
\end{tabular}

Expression of the structural genes controlling the carotenoid biosynthesis

To investigate the relationship between the carotenoid biosynthesis and the expression of the structural genes encoding carotenogenic enzymes along the growth curve, we used a semi-quantitative RT-PCR method optimized for the determination of mRNA levels in $X$. dendrorhous (Lodato et al., 2004). The idi, crtE, crtYB and crtI, genes involved in b-carotene biosynthesis pathway from IPP, and the ast gene, implicated in the end conversion of $b$ carotene to astaxanthin, and primers used are listed in Table 1. Furthermore, the expression levels of these transcripts were analyzed in the atxS2 strain to determine if its carotenoid overproducing phenotype is correlated with an increase in the expression of one or more carotenoid biosynthetic genes. In all experiments, the transcript levels were normalized in relation to the actin mRNA (Ngiam et al., 2000) which was co-amplified in each PCR reaction using the ACT 3 and ACT4 primers, designed from the published sequence of $X$. dendrorhous (Wery et al., 1996) or when necessary both carotenogenic and act genes were amplified independently. In all RT-PCR experiments the levels of actin amplicon was relatively constant in the different stages of growth.

\section{Expression of the idi gene}

The expression kinetics of idi mRNA in wild-type and atxS2 strains were similar
(Figure 2A and 2B) and their levels were approximately constant until the end of log phase. When the induction of carotenoid biosynthesis occurred (arrow on Figure 2), a decrease of idi mRNA was observed, reaching its lowest level at 45 and $50 \mathrm{~h}$ in the wild-type and mutant strains respectively. Following this, the expression of idi mRNA increased to levels that were higher in atxS2 than in the wild-type. However, in both strains the increase of idi gene expression was not associated to an increase in carotenoid production.

\section{Expression of the crtE gene}

The crtE gene expression in the wild-type strain showed a rapid increase during the log phase (Figure 2C) reaching a maximum level at the beginning of the stationary phase, point where the carotenoid biosynthesis was induced (arrow on Figure 2C). Then, the crtE mRNA levels remained constant along the stationary phase, while the production of carotenoids continued increasing. In the atxS2 strain, the expression of crtE increased slightly in the mid-log phase, and then their level was maintained until the end of the stationary phase (Figure 2D). The relative expression of crtE to act gene in stationary phase was similar in both strains. However, in the mid log phase, the crtE mRNA/act mRNA ratio was 1.9 times higher in the over-producing mutant than the wild-type strain. 

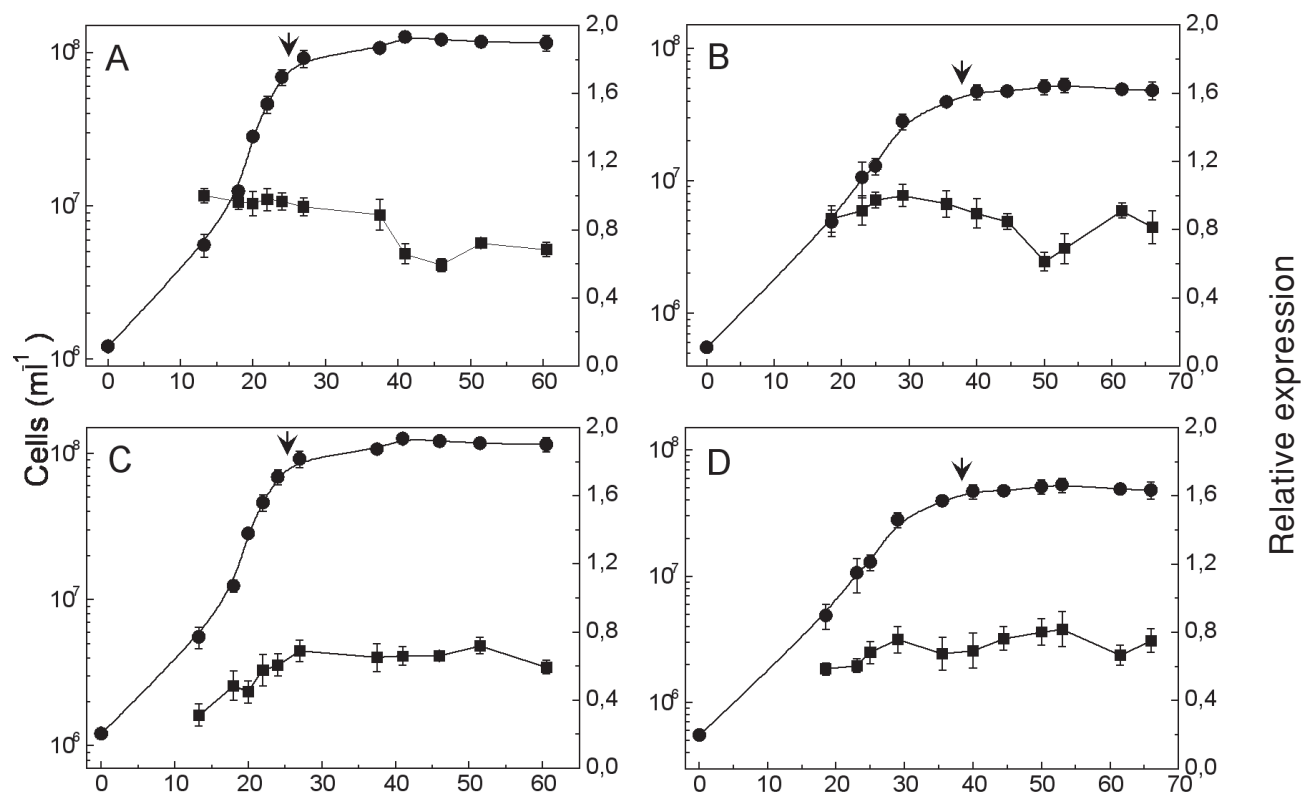

Time (h)

Figure 2: Expression kinetics of $i d i(\mathrm{~A}$ and $\mathrm{B})$ and $\operatorname{crt} \mathrm{E}(\mathrm{C}$ and $\mathrm{D})$ genes in $X$ dendrorhous cultures. The number of cells $(\bullet)$ and messenger levels $(\boldsymbol{\square})$ were determined from aliquots of UCD 67-385 (A and C) and atxS2 (B and D) cultures as described in Materials and Methods. Arrow indicates the point of carotenoid biosynthesis induction.

\section{Expression of the crtYB gene}

Since the $\operatorname{crt} Y B$ gene produces two kinds of transcripts, mature mRNA (mmRNA) and alternatively spliced mRNA (amRNA), it was necessary to use two pairs of primers to determine the levels of each (Lodato et al., 2003). The primers 11 and 15 were used for the analysis of mmRNA and primers 12 and 15 for amRNA (Table 1). In wild type and atxS2 strains the expression of both mature and alternatively spliced mRNA reached a maximum level before the start of carotenogenesis and decayed quickly in the stationary phase (Figure $3 \mathrm{~A}$ and $\mathrm{B}$ ). In the mid $\log$ phase, the ratios of $\operatorname{crt} Y B$ mmRNA/ act mRNA and amRNA/act mRNA in atxS2 were higher than the wild-type strain respectively. In the stationary phase, the expression levels of the two kinds of transcripts were very low in both strains.

\section{Expression of the crtI gene}

The crtI gene also produces a mature and alternatively spliced mRNA as described previously (Lodato et al., 2003). To determine the expression of both crtI messengers, two different primer pairs were used, 2 and 6 specific for mature mRNA and 4 and 7 specific for amRNA (Table 1). In the wild-type strain, the crtI mmRNA expression was high in exponential phase and reached a maximum level just before the point of induction of carotenoid biosynthesis. At the end of the log phase the transcript level decayed slowly up to $38 \mathrm{~h}$ in the stationary phase, followed by a rapid decrease (Figure 3C), in spite of a continued increase in the cellular concentration of carotenoids (not shown). Contrary to crtI mmRNA, the level of alternative crtI transcript in the wild-type strain continued increasing after the induction of carotenoid biosynthesis and began to fall after $44 \mathrm{~h}$ of culture. The ratio crtI $\mathrm{mmRNA} / \mathrm{amRNA}$ ratio diminished during the growth cycle, showing high values at the begining of the log phase. Therefore, in early stages of cultivation there are higher amounts of crtI transcripts that could be processed to the mature form 
and translated into phytoene desaturase enzyme, contrary to what happens in stationary phase. In the atxS2 strain (Figure $3 \mathrm{D})$ the mmRNA reached a high level early before the induction of carotenoid synthesis and then showed a slower linear decay. In relation to crtI amRNA (Figure 3D), the kinetics of expression was irregular, presenting two peaks in the mid log and stationary phase. In addition, in the mid log phase, the crtI mmRNA/act mRNA ratio was 1.9 fold higher in the mutant $(0.90)$ than in the wild-type strain (0.47). In general the crtI mmRNA/amRNA ratio diminished with the growth curve.

Expression of astaxanthin synthase gene (ast)

As is shown on Figure 4A, in the wild-type strain the ast mRNA levels increased during the log phase, reaching its maximum level when the carotenoid biosynthesis was induced (arrow). However, this increasing level was transient and the ast transcript gradually decayed from $27 \mathrm{~h}$, although the carotenoid production was still increasing. A similar expression kinetics was observed in the atxS2 mutant, but the expression decay was not as evident as in the wild-type strain (Figure 4B). The level of ast mRNA in the mutant strain was more than twice the level reached in the wild-type strain at the beginning and at the end of the growth curve. However, the maximum level reached was similar in both strains.

\section{DISCUSSION}

Carotenoids production and other variables during the growth curve of $\mathrm{X}$. dendrorhous.

The $X$. dendrorhous wild-type strain has a low specific carotenoid production ( $\mathrm{mg}$ per $\mathrm{g}$ of dry-weight of yeast) in the early stage of culture, and tends to decrease at the mid log phase. A similar profile was observed in atxS2 mutant cultures, and although the biomass was only $42 \%$ of the wild-type, the

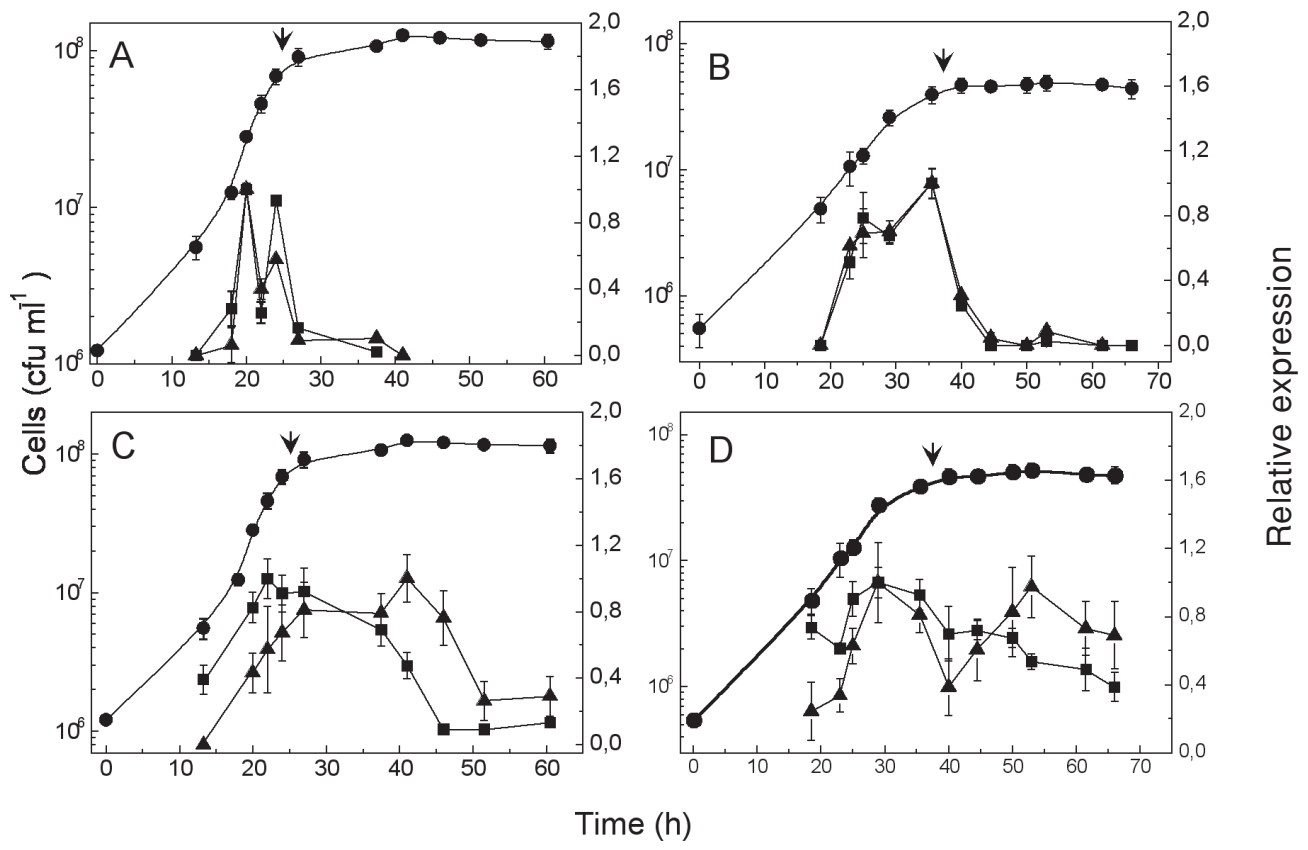

Figure 3: Expression kinetics of $\operatorname{crt} \mathrm{YB}(\mathrm{A}$ and $\mathrm{B})$ and $c r t \mathrm{I}(\mathrm{C}$ and $\mathrm{D})$ genes in $X$. dendrorhous $\mathrm{UCD}$ 67-385 (A and C) and atxS2 (B and D) strains. (O), numbers of cells; ( $\mathbf{\square}$ ), relative expression of mature mRNA (mmRNA); $(\boldsymbol{\Delta})$, relative expression of alternative mRNA (amRNA). Arrow indicates the point of carotenoid biosynthesis induction. 
cellular concentration of carotenoids was greater (Lodato et al., 2003). In both strains, induction of carotenoid biosynthesis was observed at the beginning of the stationary phase suggesting that the carotenoid production was associated to the age and lower growth rate of the culture (Fang and Chen, 1993). Interestingly, the carotenoid biosynthesis was induced after glucose depletion and the beginning of ethanol consumption in both cultures. The production of carotenoids increased while the concentration of ethanol in the culture media diminished, in accordance to previously described results (Yamane et al., 1997). In addition, under fermentative or aerobic culture conditions a marked decrease or increase in astaxanthin synthesis was observed respectively. Johnson and Lewis, 1979 suggested that an aerobic metabolism is favorable to astaxanthin production, since carbon sources such as succinate are only used aerobically. In this work, the maximum concentration of ethanol was reached before carotenoid synthesis induction, ranging from 0.1 to $0.15 \%$, with a higher carotenoid production in the mutant strain. The addition of $0.2 \%$ ethanol during the lag and active
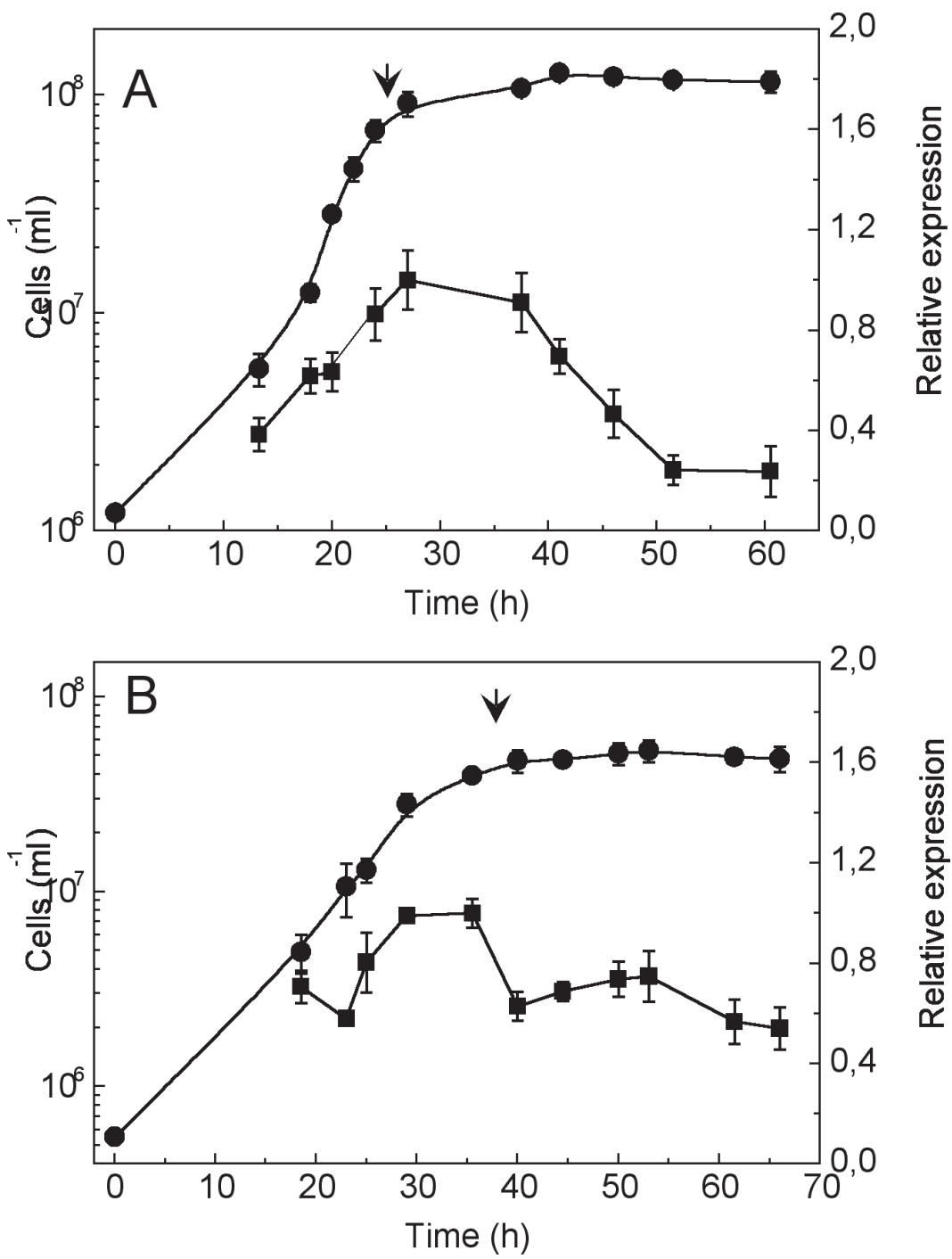

Figure 4: Expression kinetics of ast gene in X. dendrorhous cultures. The number of cells $(\bigcirc)$ and mRNA levels ( $\boldsymbol{\square}$ ) were determined from aliquots of UCD 67-385 (A) and atxS2 (B) cultures as described in Materials and Methods. Arrow indicates the point of carotenoid biosynthesis induction. 
growth phases of $X$. dendrorhous cultures increased the specific rate of carotenoid production ( $\mathrm{Gu}$ et al., 1997). Therefore, according to our results, the exogenous addition of ethanol could mimic a naturally occurring process of induction of carotenoid biosynthesis, but the mechanism of this induction is unknown.

In addition, the results suggest that the atxS2 strain could be deregulated in the carotenoid biosynthesis since it is not sensitive to environmental changes, such as culture medium (Lodato et al., 2004). A consequence of the deregulated production of carotenoids of the axtS2 strain could be a decrease in biomass compared to the wildtype strain (Table 2), results in agreement with other overproducer mutants (Yamane et al., 1997). It is possible that cellular resources were not available for other metabolic pathways, including cell growth. In fact, after the introduction of carotenoid biosynthesis genes from Erwinia uredovora into a non carotenogenic yeast Candida utilis, the recombinant strain produced lycopene but the ergosterol content decreased by $35 \%$, and the growth rate was half with respect to the control strain (Miura et al., 1998).

\section{Expression of structural genes controlling the carotenoid biosynthesis pathway}

In general, the expression of carotenogenic genes in the wild-type strain showed an increase in the early phases of growth, reaching a maximum level in the period of induction of carotenoid biosynthesis. However, this increase was transitory since their mRNA levels decayed later on, with exception of the crtE gene. A surprising fact is that from the end of the log phase the cellular concentration of carotenoids increases, although the expression levels of almost all carotenogenic mRNAs diminished. An explanation could be that the necessary enzymes for carotenoid production are maintained stable for a long time in stationary phase making possible the carotenoid synthesis.

In the early log phase of growth, the levels of crtE, crtYB, crtI and ast messengers in the astaxanthin over producer strain are about twice the levels observed in the wildtype strain. The difference in gene expression could explain, at least partially, that carotenoid biosynthesis in strain atx 2 is deregulated from the beginning of the culture growth. Along the stationary phase, the level of ast mRNA from strain atxS2 was about 3 times higher than the wild-type, and also its level remained higher for a longer time. On the other hand, these results suggest that crtE, crtI and ast could be regulated by glucose. Keeping this in mind, carotenoid production per unit of biomass described in the wild-type strain was higher when cellobiose, ethanol or other carbon sources other than glucose were used (Johnson and Lewis, 1979, An et al., 1989). In fact, it is interesting that the cellular concentration of carotenoids increases when glucose has been depleted from the media and ethanol is utilized as a carbon source (non fermentable). Furthermore, in $X$. dendrorhous it has been observed that an increase in the oxygenation of cultures avoids the synthesis of ethanol and induces a higher cellular concentration of carotenoids (Yamane et al., 1997). In non restrictive lower oxygenation conditions, the expression of the carotenogenic genes could respond to the oxygen concentration in the media. Given the close relationship between carbon metabolism, carotenoid synthesis and oxygenation level in $X$. dendrorhous, it can be speculated that the carotenogenic (with the exception of the gene idi) and mitochondrial genes could respond to a global transcriptional regulator of carbon and oxygen.

The fact that the synthesis of carotenoids in $X$. dendrorhous is induced under aerobic metabolism could be related to the antioxidant properties of carotenoids, especially astaxanthin (Schroeder and Johnson, 1993, 1995a, 1995b). It has been determined that the oxygen free radicals are a by-product of the aerobic metabolism and that the mitochondria are the main sources of oxidizers since they consume approximately $85 \%$ of the oxygen used by the cells (Shigenaga et al., 1994, Bailey and Cunningham, 2001). Schroeder and Johnson (1995b) sustain that $X$. dendrorhous does not possess the superoxide dismutase 
cytosolic form and the carotenoids could compensate this absence. On the other hand, as previously mentioned, the carotenoid synthesis in $X$. dendrorhous could be a mechanism against oxidizing compounds synthesized in the plants where this yeast lives.

The expression of the $\operatorname{crtYB}$ gene presents a two-phase kinetics in wild-type and mutant strains. In Mucor circinelloides, the expression of the carRP gene homologous to $\operatorname{crt} Y B$, responds to blue light. The exposure of the mycelium to two different pulses of blue light followed by incubation at different times in darkness, produced a two-phase kinetics of the carRP level messenger (Velayos et al., 2000) although an interpretation of the two-phase kinetics of expression has not been proposed. In Neurospora crassa, although there is an increase in the mRNA of the phytoene- $\beta$-carotene synthase gene as a response to blue light, the kinetics is not in two-phases (Schmidhauser et al., 1994). However, the experimental conditions employed were different, since the analysis involved the exposure to continuous light. Additionally, in the fungus Phycomyces blakesleeanus whose carotenoid synthesis responds to light, there is no information about the expression of phytoene- $\beta$ carotene synthase.

According to the results obtained in this work, the regulation of carotenoid synthesis in $X$. dendrorhous can be divided into two stages. In the first stage, considered to occur in the log phase, the enzymatic complexes involved in the carotenoid synthesis could assemble. During this stage where there is a high availability of carbon and nitrogen sources, the cellular resources such as energy, cofactors and intermediates (acetyl coenzyme A, IPP) could be used mainly in the metabolic pathway destined for increment in biomass. In the second stage, when the growth rate diminishes, the metabolic intermediates could be redirected towards the previously formed carotenogenic complexes inducing carotenoid biosynthesis. An interesting aspect is that the relative expression of the crtE gene was maintained approximately constant at the end of log phase, contrary to the other carotenogenic genes. This suggests that a high level of GGPP synthase would allow a flow of isoprenoid precursors toward the carotenogenic and related pathways, such as biosynthesis of ergosterol, quinones and others. The carotenoid synthesis in $X$. dendrorhous is a complex process which could be regulated at multiple levels involving the concentration of carotenogenic gene messengers, the alternative splicing of at least two of these messengers (Lodato et al., 2003), the flow of metabolic intermediates among different pathways and possibly the level of the carotenogenic proteins and their enzymatic activities.

\section{ACKNOWLEDGEMENTS}

This work was supported by Fondecyt 1040450 , by Acciones Integradas agreement between Universidad de Chile (Chile) and C.S.I.C. (Spain), Mecesup UCH 0106 by a graduate scholarship to Jennifer Alcaíno and Mauricio Niklitschek and Deutscher Akademischer Austanschdienst (DAAD) by a graduate scholarship to $\mathrm{P}$. Lodato and A. Wozniak.

\section{REFERENCES}

AN GH, (1997). Photosensitization of the yeast Phaffia rhodozyma at a low temperature for screening carotenoid hyperproducing mutants. Appl. Biochem. Biotechnol. 66: 263-268

AN GH, JOHNSON EA (1990). Influence of light on growth and pigmentation of the yeast Phaffia rhodozyma. Antonie van Leeuwenhoek. 57: 191-203

AN GH, Schuman DB, Johnson E (1989) Isolation of Phaffia rhodozyma mutants with increased astaxanthin content. Appl. Environ. Microbiol. 55: 116-124

ANDREWES AJ, PHAFF H, STARR M (1976). Carotenoids of Phaffia rhodozyma. A red-pigmented fermenting yeast. Phytochem.15: 1003-1007

ARMSTRONG GA (1994) Eubacteria show their true colors: Genetics of carotenoid pigment biosynthesis from microbes to plants. J. Bacteriol. 176: 4795-4802

BAILEY SM, CUNNINGHAM CC (2001). Contribution of mitochondria to oxidative stress associated with alcoholic liver disease. Free Radic. Biol. Med. 32: 1116

BON JA, LEATHERS TD, JAYASWAL RK (1997) Isolation of astaxanthin-overproducing mutants of Phaffia rhodozyma. Biotechnol. Lett. 19: 109-112

CHOMCZYNSKI, P, SACCHI N (1987) Single-step method of RNA isolation by acid guanidinium thiocyanate-phenol-chloroform extraction. Anal. Biochem. 162: 156-159 
ENTIAN KD, Y SCHÜLLER HJ (1997) Glucose repression (carbon catabolite repression) in yeast. In F. K. Zimmermann y K.-D. Entian (eds.), Yeast sugar metabolism: Biochemistry, genetics, biotechnology, and applications. Pp 409-434. Technomic Publishing Company, Inc., USA

FANG TJ, CHEN YS (1993) Improvement of astaxanthin production by Phaffia rhodozyma through mutation and optimization of culture conditions. J. Ferment. Bioeng. 75: 446-469

GANCEDO J (1998) Yeast carbon catabolite repression. Microbiol. Mol. Biol. Rev. 62: 334-361

GU WL, AN GH, JOHNSON EA (1997) Ethanol increases carotenoid production in Phaffia rhodozyma. 1997. J. Ind. Microbiol. Biotechnol. 19: 114-117

JOHNSON EA (2003) Phaffia rhodozyma: colorful odyssey. Int. Microbiol. 6: 169-174

JOHNSON EA, LEWIS M (1979) Astaxanthin formation by the yeast Phaffia rhodozyma. J. Gen. Microbiol. 115: $173-183$

JOHNSON EA (1977) The yeast Phaffia rhodozyma as a dietary pigment source for salmonids and crustaceans. J. Fish. Res. Board Can. 34: 2417-2421

KAJIWARA P, FRASER PD, KONDO K, MISAWA N (1997) Expression of an exogenous isopentenyl diphosphate isomerase gene enhances isoprenoid biosynthesis in Escherichia coli. Biochem. J. 324: 421426

KAL AJ, VAN ZONNEVELD AJ, BENES V, VAN DEN BERG M, GROOT KOERKAMP M, ALBERMANN K, STRACK N, RUIJTER JM, RICHTER A, DUJON B, ANSORGE W, TABAK HF (1999) Dynamics of gene expression revealed by comparison of serial analysis of gene expression transcript profiles from yeast grown on two different carbon sources. Mol. Biol. Cell. 10: 1859-1872

KWAST KE, BURKE P, POYTON RO (1998) Oxygen sensing and the transcriptional regulation of oxygenresponsive genes in yeast. J. Exp. Biol. 201: 1177-1195

LEWIS MJ, RAGOT N, BERLANT MC, MIRANDA M (1990) Selection of astaxanthin-overproducing mutants of Phaffia rhodozyma with b-ionone. Appl. Environ. Microbiol. 56: 2944-2945

LODATO P, ALCAÍNO J, BARAHONA S, RETAMALES $P$, CIFUENTES V (2003) Alternative splicing of transcripts from crtI and $\operatorname{crtYB}$ genes of Xanthophyllomyces dendrorhous. Appl. Environ. Microbiol. 69: 4676-4682

LODATO P, ALCAÍNO J, BARAHONA S, RETAMALES P, JIMÉNEZ A, CIFUENTES V (2004) Study of the expression of carotenoid biosynthesis genes in wild-type and deregulated strains of Xanthophyllomyces dendrorhous (Ex.: Phaffia rhodozyma). Biol. Res. 37: 83-93

LORENZ RT, CYSEWSKI GR (2000) Commercial potential for Haematococcus microalgae as a natural source of astaxanthin. TIBTECH. 18: 160-167

MEYER PS, DU PREEZ JC (1994) Effect of culture conditions on astaxanthin production by a mutant of Phaffia rhodozyma in batch and chemostat culture. Appl. Microbiol. Biotechnol. 40: 780-785

MILLER MW, YONEYAMA M, SONEDA M (1976) Phaffia, a new yeast genus in the Deuteromycotina (Blastomycetes). Int. J. Syst. Bacteriol. 26: 286-291

MIURA Y, KONDO K, SAITO T, SHIMADA H, FRASER PD, MISAWA N (1998). Production of the carotenoids lycopene, b-carotene y astaxanthin in the food yeast Candida utilis. Appl. Environ. Microbiol. 64: 12261229
NGIAM C, JEENES DJ, PUNT PJ, VAN DEN HONDEL CAMJJ, ARCHER DB (2000) Characterization of a foldase, protein disulfide isomerase $\mathrm{A}$, in the protein secretory pathway of Aspergillus niger. Appl. Environ. Microbiol. 66: 775-782

NIGOYI KN, BJÖRKMAN O, GROSSMAN AR (1997) The roles of specific xanthophylls in photoprotection. Proc. Natl. Acad. Sci. USA. 94: 14162-14167

RETAMALES P, HERMOSILLA G, LEÓN R, MARTÍNEZ C, JIMÉNEZ A, CIFUENTES V (2002) Development of the sexual reproductive cycle of Xanthophyllomyces dendrorhous. J. Microbiol. Methods. 48: 87-93

RETAMALES P, LEÓN R, MARTÍNEZ C, HERMOSILLA G, PINCHEIRA G, CIFUENTES V (1998) Complementation analysis with new genetics markers in Phaffia rhodozyma. Antonie van Leeuwenhoek. 73: 229-236

RETAMALES P, SEPÚLVEDA D, NIKLITSCHEK M, BARAHONA S, LOZANO C, CARMONA M, REYES E, CIFUENTES V (2003) Genetic dissection of the stages of development of sexual reproductive cycle in X. dendrorhous. Biol. Res. 36: R74

SCHMIDHAUSER TJ, LAUTER FR, SCHUMACHER M, ZHOU W, RUSSO VEA, YANOFSKY C (1994) Characterization of $a l-2$, the phytoene synthase gene of Neurospora crassa. J. Biol. Chem. 269: 12060-12066

SCHROEDER WA, JOHNSON EA (1993) Antioxidant role of carotenoids in Phaffia rhodozyma. J. Gen. Microbiol. 139: 907-912

SCHROEDER WA, JOHNSON EA (1995a) Singlet oxygen and peroxyl radicals regulate carotenoid biosynthesis in Phaffia rhodozyma. J. Biol. Chem. 270: 18374-18379

SCHROEDER WA, JOHNSON EA (1995b) Carotenoids protect Phaffia rhodozyma against singlet oxygen damage. J. Ind. Microbiol. 14: 502-517

SHIGENAGA MK, HAGEN TM, AMES BN (1994) Oxidative damage and mitochondrial decay in aging. Proc. Natl. Acad. Sci. USA. 91: 10771-10778

VELAYOS A, ESLAVA AP, ITURRIAGA EA (2000) A bifunctional enzyme with lycopene cyclase and phytoene synthase activities is encoded by the carRP gene of Mucor circinelloides. Eur. J. Biochem. 267: 5509-5519

VERDOES JC, KRUBASIK P, SANDMANN G, VAN OOYEN AJJ (1999a) Isolation and funtional characterisation of a novel type of carotenoid biosynthetic gene from Xanthophyllomyces dendrorhous. Mol. Gen. Genet. 262: 453-461

VERDOES JC, MISAWA N, VAN OOYEN AJJ (1999b) Cloning and characterization of the astaxanthin biosynthetic gene encoding phytoene desaturase of Xanthophyllomyces dendrorhous. Biotechnol. Bioeng. 63: $750-755$

VISSER H, VAN OOYEN AJJ, VERDOES JC (2003) Metabolic engineering of the astaxanthin-biosynthetic pathway of Xanthophyllomyces dendrorhous. FEMS Yeast Res. 4: 221-231

WERY J, DALDERUP MJM, TER LINDE J, BOEKHOUT T, VAN OOYEN AJJ (1996) Structural and phylogenetic analysis of the actin gene from the yeast Phaffia rhodozyma. Yeast. 12: 641-651

YAMANE YI, HIGASHIDA K, NAKASHIMADA Y, KAKIZONO T, NISHIO N (1997) Influence of oxygen and glucose on primary metabolism and astaxanthin production by Phaffia rhodozyma in batch and fedbatch cultures: kinetic and stoichiometric analysis. Appl. Environ. Microbiol. 63: 4471-4478. 